\title{
Synergistic Evaluation and Constraint Factor Analysis on Urban Industrial Ecosystems of Traditional Industrial Area in China
}

\author{
Chengpeng Lu $\mathbb{D},{ }^{1,2,3}$ Wei Ji, ${ }^{1}$ Zhiliang Liu, ${ }^{1}$ Shuheng Dong, ${ }^{2,3}$ and Bing Xue $\mathrm{e}^{2,3}$ \\ ${ }^{1}$ Institute of County Economic Development \& Rural Revitalization Strategy, Lanzhou University, Lanzhou 730000, China \\ ${ }^{2}$ Key Lab of Pollution Ecology and Environmental Engineering, Institute of Applied Ecology, Chinese Academy of Sciences, \\ Shenyang 110016, China \\ ${ }^{3}$ Key Lab for Environmental Computation and Sustainability of Liaoning Province, Shenyang 110016, China \\ Correspondence should be addressed to Chengpeng Lu; lcp@lzu.edu.cn
}

Received 15 May 2020; Revised 6 June 2020; Accepted 11 June 2020; Published 1 July 2020

Guest Editor: Jun Yang

Copyright (c) 2020 Chengpeng Lu et al. This is an open access article distributed under the Creative Commons Attribution License, which permits unrestricted use, distribution, and reproduction in any medium, provided the original work is properly cited.

\begin{abstract}
Industrial ecology is an advanced form and ideal model of modern industrial development, in which the industrial ecosystem is the core. Based on the PSR model, this paper builds a comprehensive evaluation index system for urban industrial ecosystem development and selects 14 prefecture-level cities in Liaoning Province of the traditional industrial area in Northeastern China as cases to calculate the development level of its industrial ecosystem during 2000-2018 using an improved Topsis method and then to conduct a spatial visualization analysis. Finally, based on the "stress-state-response" subsystem, this paper diagnoses the constraints for industrial ecosystem development, which can provide a reference basis for decision-making in industrial ecology of traditional industrial area represented by those in Northeast China. The results show the following: (1) From 2000 to 2018, the industrial ecology of the 14 cities in Liaoning Province was at a medium level. Except for Shenyang and Dalian with the rapid development, the difference of industrial ecosystem development for other cities was relatively small. (2) From 2000 to 2018, the industrial ecosystem development of each city was in a status of "either increasing, or decreasing, or fluctuating," which generally raised first and then decreased. Regarding spatial difference, the development exhibited a "center-periphery" pattern, with Shenyang and Dalian as the "dual-core" that were increasingly strengthened with significantly high-level industrial ecology. (3) At system level, PSR constraint grades for the industrial ecosystem development in the 14 cities of Liaoning Province were different. Constraint grades in the pressure subsystem, the state subsystem, and the response subsystem for the industrial ecosystem of Liaoning were $45.73 \%, 20.01 \%$, and $34.34 \%$, respectively, indicating that the lack of human response to the ecological environment and the pressure of human activities on the ecological environment during the industrial economy development were the main constraints affecting the process of industrial ecology in these cities. (4) Due to the differences in geographical environments, economic bases, industrial structures, and local development contexts, the major constraint factors of industrial ecosystem development in different cities are significantly different and complicated; however, there are five factors that are generally considered as major constraint factors in all cities, i.e., regional GDP, number of labor force employed in the secondary industrial sector, gross investment in fixed assets, amount of industrial sulfur dioxide removal, and production value from "three-wastes" comprehensive utilization. At last, this paper puts forward some recommendations and suggestions for providing scientific support for industrial ecosystem construction in the traditional industrial area of Northeastern China.
\end{abstract}

\section{Introduction}

Industrial ecosystem is a complex system formed by feedback and coupling between industry and ecological environment [1-3]. It is an organic whole formed by material exchange and energy flow between industrial segments and environmental components in a certain area $[4,5]$, with general features of subject diversity, structural complexity, synergetic evolution, and systematic stability [6-8]. In this system, the quantitative relationship between input and output, supply and demand of different industries, appears as the static aspect of the industrial system, while the 
interaction and restriction between industries in intermediate production processes appears as the dynamic aspect [9]. In the process of continuous development and evolution of the industrial ecosystem, it is affected by a continuous interweaving and integration of various internal and external factors in both spatial and temporal dimensions [10-12]. The change of one (or a group of) element(s) in the system may cause a spatial and temporal change in other elements and even in the entire system [13]. As a typical subsystem of complex urban system $[14,15]$, the industrial ecosystem usually interacts, integrates, and collaborates with the complex urban system in all aspects including economy, culture, society, and ecology [16]. On the one hand, a rapidly developed ecological industry has an inestimable role in promoting the economic vitality of the urban system and protecting the ecological environment. On the other hand, the industrial ecosystem, as a carrier of industrial ecosystem activities, is always impacted directly or indirectly by the construction and development methods of the city [17]. Therefore, to achieve regional sustainable development, we should pay high attention to the ecological and environmental effects of industry transformation in both spatial and temporal dimensions, thus realizing the coordinated development of industry and environment $[18,19]$. At present, the research on industrial complexity is shifting from evolution of complexity of industrial system to adaptability of industrial ecosystem [20], which provides a new theoretical and methodological paradigm for exploring the coupling mechanism of the industrial ecosystem [21], and has a very good application prospect [22].

Interaction through material flow, etc., between components and subsystems of the industrial ecosystem shapes a topological structure of ecological relationships, in which the evolution of this structure and diagnosis of impact factors in this process are essential for the transformation of urban industrial ecosystems [23]. Either in China or abroad, the research in transformation of industrial ecosystems mainly focuses on industrial metabolic analysis, industrial chain analysis, cleaner production, and ecological design. Ayres first proposed the concept of industrial metabolism [24]. Based on this concept, Frosch and Gallopoulos [4] proposed the industrial metabolism theory, that is, through the recycling process of natural ecosystems to study the industrial metabolism process. Chopra et al. $[25,26]$ regarded the industrial ecosystem as a natural ecosystem and studied its metabolic processes. Furtherly, Lu [19] built a waste metabolism model of industrial ecosystems and conducted a quantitative analysis on the waste metabolism process and characteristics of Jinchang's industrial symbiosis system. Industrial chain analysis mainly refers to starting from adjusting the structure and composition of an industrial chain to study the urban ecological transformation through the industrial chain reorganization and the analysis of the industrial chain stability, for example, Japan's Eco-town [27], and the industrial symbiosis formed by a green industrial supply chain of Guangxi Guitang Corporation in China [28]. In addition, Zhang [29] conducted the analyses on urban industrial ecological transformation from the perspective of stability. In recent years, more and more scholars in China and abroad have paid great attentions to the related research on industrial ecosystem development rules and its comprehensive evaluation. Huang and Ulanowicz [30] took the indicators of the ecological network analysis method to evaluate the economic development trend of Beijing. Zhang et al. [31] applied the Input-Output table based ecological network analysis method to analyze the nutritional structure and the symbiotic relationship between the components of Beijing's industrial ecological network. Qiu et al. [18] selected 14 mining cities in Northeast China as research cases and quantitatively evaluated the adaptability of the industrial ecosystems in mining cities. Wang and Zhou [32] studied the spatial characteristics of ecological-economic interaction in China's industrial ecological-economic system based on PSR Model and then identified the key influencing factors of different types of interaction relationships based on multiple discrete choice model. Currently, some progress has been made in comprehensive evaluation and empirical research about industrial ecosystems, but there still exist some common problems: (1) existing research mainly focuses on the use of coordination index, discrete models, or coupling relationship to carry out industrial ecological security evaluation; however, it will generate a major error when converting the originally constructed index into the coordination index, which has no sense to the ecological and economic significance of the original index, and is not conducive to the analysis of the reasons; (2) there is still a lack of researches on the comprehensive evaluation of the development level of industrial ecosystem, and the diagnosis of impact factors; (3) the solution to future industrial ecological construction and co-governance has not been put forward in accordance with the impact factors.

Since the 1980s, the human-land relationship in the traditional industrial area in Northeast China has become increasingly tense. The extensive development pattern has not only caused environmental pollution and waste of resources, but also become a major direct constraint on economic growth $[33,34]$. Particularly in mining cities, there have been a series of economic, social, and environmental issues such as stagnated economic development, severe disguised unemployment, and deteriorated ecological environment, which have aroused a great concern of the government $[35,36]$. In 2003, the Central Committee of the Communist Party (CCCP) and the State Council of China jointly issued an official document "Several Opinions on Implementation of the Strategy for Revitalizing Old Industrial Bases in Northeast China" (as Revitalization Strategy thereafter) and formulated various guidelines and policies for the Revitalization Strategy; in 2007, the State Council approved the "Revitalization Plan for the Northeast Region" (as Revitalization Plan thereafter) and clearly proposed that the Northeast Region would be built into an important economic growth region with a high level of comprehensive economic development and an essential safeguarding zone for national ecological security; in 2016, the CCCP and the State Council jointly issued another official document "Several Opinions on Comprehensively Rejuvenating Old Industrial Bases in the Northeast and 
Other Regions" (as Rejuvenation Opinions thereafter). This document clearly reiterated that it was important to promote sustainable development of resource-based cities, and strive for the coordinated social and economic development of resource-based and non-resource-based industries in urban areas and mining areas. Since the implementation of the above policies and plans, the economic and social development in the traditional industrial area in Northeast China was accelerated; the economic strength was continuously enhanced; the pilot of economic transformation of resourcebased cities was steadily advanced; the infrastructure was constantly improved; the ecological construction and environmental protection had achieved positive outcomes; an urban social security system was preliminarily established; and the employment situation showed an upward turn [37]. However, in the transformation process of the traditional industrial area for undertaking industrial transfer, nurturing alternative industries, and transforming towards sustainable development from resource-based cities, Northeast China has not completely come out of the traditional energyconsuming production model. This is because the one-way industrial economic development model ignored the ecological capacity and therefore paid a high price at sacrificing limited resources and natural environment which humans live on. Consequently, for resource-based cities, especially resource-depleted cities, sustainable development capabilities become weak, development of alternative industries is slow, and social, ecological, and environmental issues are still serious [38-42]. To avoid the sharp conflict between the traditional industrial system and natural ecosystem in the process of industrial succession, transformation of mining cities becomes vital. The core of such transformation is to improve the level of industrial ecology. Thus, the scientific review and research into comprehensive measurement and constraint factor diagnosis for urban industrial ecosystem development are particularly urgent.

In this study, 14 prefecture-level cities in Liaoning Province of traditional industrial area in Northeastern China were selected as examples. Taking the industrial ecosystem as an entry point, we systematically evaluate the development of industrial ecology of Liaoning Province during 2000-2018, at a city scale. Meanwhile, we explore the development trend of industrial ecology, temporal evolution and spatial distribution characteristics, and reveal the impact factors. Overall, this study aims to look for a specific path of development for optimizing industrial ecosystem for urban areas in Liaoning. In the process of implementing the Rejuvenation Opinions and "the Revitalization Plan," it not only can provide new ideas and decision-making evidences to maintain sustainable development of the industrial system and improve the competitiveness in industrial development for Liaoning Province, but also can provide references for industrial ecology in other traditional industrial areas.

\section{Materials and Methods}

2.1. Studied Cases. Liaoning Province is located in the south of China's northeast region (Figure 1), with a land mass of 148,000 square kilometers. It administers 14 prefecture- level cities and 100 counties (including county-level cities and districts) with a total population of 42.71 million. As one of China's important old industrial bases, Liaoning Province has almost all industrial categories, including 39 large, 197 medium, and more than 500 small industrial categories. In Liaoning, equipment manufacturing and raw material industries are well developed. Many industries occupy an important position in the country, such as major equipment manufacturing for metallurgy and mining, electric power transmission and transformation, general petrochemical processing, metal processing, iron and steel, and petrochemical industries. In 2018, the regional GDP in Liaoning was CNY2531.54 billion, of which the added value of the secondary industry was CNY1002.51 billion, accounting for $35.6 \%$. Building a strong ecological province is a strategic priority for Liaoning Province in revitalizing Northeast China. The coordinated development of industrial ecology has already attracted widespread attention. Since the implementation of the Revitalization Strategy, the transformation and optimization of traditional industries in Liaoning has continuously accelerated, while the economic development focus has shifted from high-speed to high-quality, and the development of major equipment design and manufacturing industry has taken a lead in the country. However, due to the long-term influence of the extensive economic growth model, the industrial development pattern has not fundamentally changed yet, which still mainly relies on traditional industries such as equipment manufacturing, coal mining, and oil smelting. Governments and enterprises at all levels overemphasized industrial development but failed to effectively integrate industries into industrial ecosystem construction, thus resulting in a relatively independent industrial system without comprehensive interconnection between industrial categories. Consequently, the development of industrial ecology was slow, industrial structures were convergent, and the complementary regional advantages were not effectively exerted. In addition, the independent innovation capability of industrial ecosystem was weak. It always depended on traditional industrial paths and lacked enough nurture of emerging pillar industries, featuring a low level of industrial structure and an overweighed secondary sector. In the meantime, there lacked an effective dynamic circulation system, high-tech industries and modern service industries were proportionally low, the deep processing of raw material industry was at a relatively low level, and the independent innovation ability was weak. Constructing industrial ecosystems is a new strategic measure to promote the comprehensive revitalization of the Northeast Region. It can effectively address deep-seated issues in industrial development of the traditional industrial area in Liaoning, overcome constraints of traditional industrial development systems and mechanisms, change the industrial development approach in multiple dimensions such as management mechanism, operation mode, production method, and business environment, and realize an economic-environmental coupling and sustainable development $[43,44]$. 


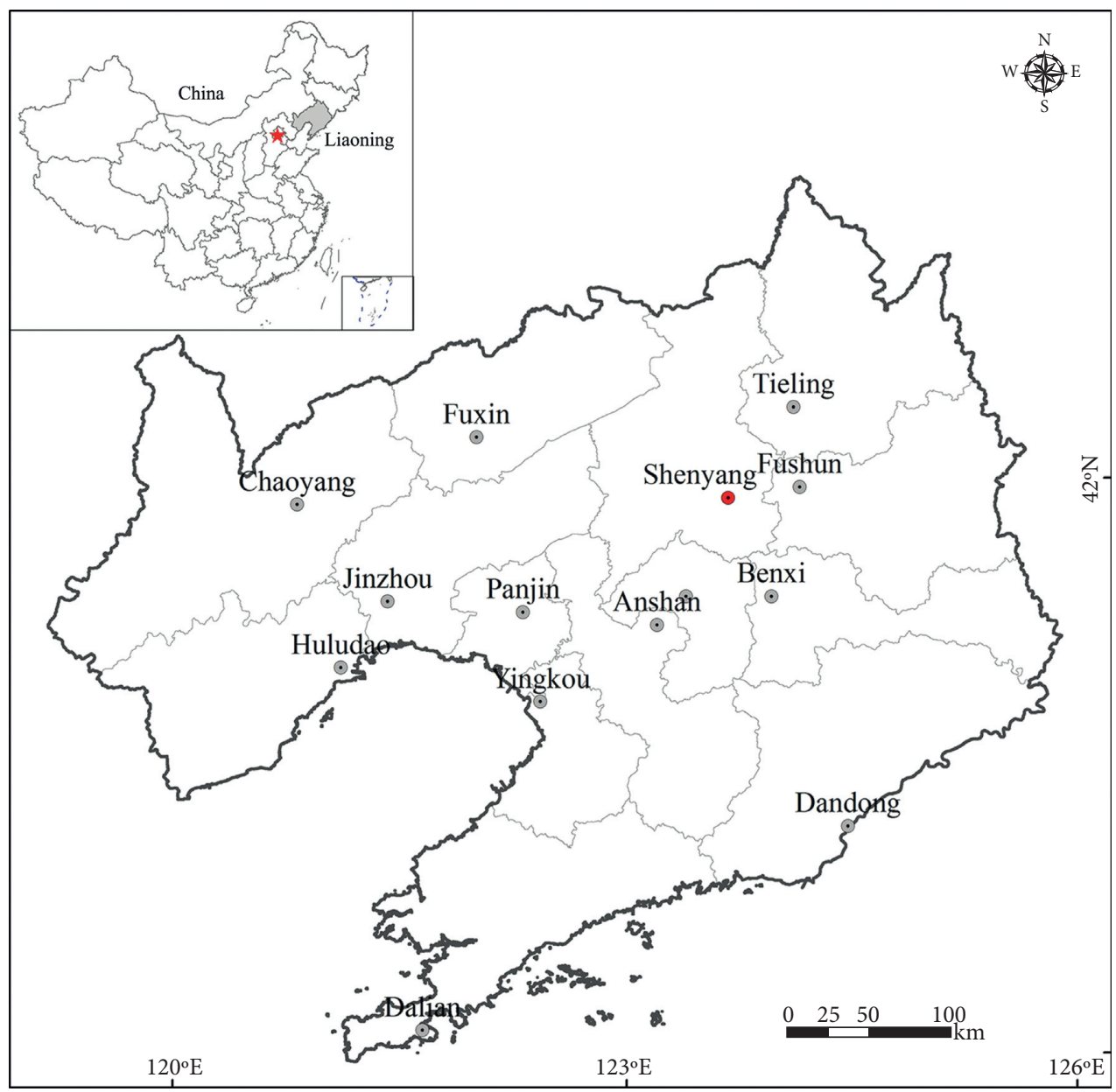

FIgURE 1: Location of the studied cities.

2.2. Index and Data Sources. Constructing a scientific and rational evaluation index system is the basis and premise to objectively evaluate an urban industrial ecosystem. Based on the PSR model, in terms of local contexts, operability, and rationality, this paper establishes a comprehensive evaluation index system of urban industrial ecosystem development, with fully considering the complexity, dynamics, and openness of an urban industrial ecosystem, following the principles of systematicity, comparability, and availability, and taking the system's internal structure and benefit optimization as the foothold. The evaluation index system (Table 1) includes three layers: (1) pressure subsystem, which represents the development need of the industrial economy and the pressure of energy consumption on the ecosystem; (2) state subsystem, which represents the impact on the ecological environment during the development of industrial economy and the original state of ecological environment; (3) response subsystem, which characterizes the human's effect to protect the environment and control pollution in order to alleviate environmental damage when the ecological environment is changed due to the impact of industrial economic development. The data are mainly from "Liaoning Statistical Yearbooks," China City Statistical Yearbooks, statistical yearbooks, and environmental statistical bulletins of various cities in Liaoning Province, published during 2001-2019.

2.3. Methodology: TOPSIS. This paper adopts the TOPSIS (Technique for Order Preference by Similarity to an Ideal Solution) method to objectively quantitatively measure and analyze the development level of urban industrial ecosystem in Liaoning Province. The TOPSIS method, proposed by Hwang and Yoon in 1981, is commonly used for comprehensive evaluation and comparison of multiple options in multi-attribute decision-making theory [45]. Its basic principle is to eliminate the difference among various indicators due to different units through related standardized processing methods, establish a normalized matrix from the original data, and then identify the best and worst ones from the various solutions. By calculating the distance between each solution and the best/worst solution, we can work out the relative closeness between the selected solution and the worst or the best solution, to rank and evaluate the advantages and disadvantages of different solutions. When calculating a normalized decision matrix using the TOPSIS method, all indicators are normalized with the perception of the bigger the better, without classifying indicators. In 
TABLE 1: PSR model based evaluation index system for urban industrial ecosystems in Liaoning Province.

\begin{tabular}{|c|c|c|c|c|c|}
\hline $\begin{array}{l}\text { System } \\
\text { layer }\end{array}$ & Normative level & Parameters & Indicator & Parameters & $\begin{array}{c}\text { Indicator } \\
\text { type }\end{array}$ \\
\hline \multirow{9}{*}{ Pressure } & \multirow{7}{*}{ Industrial economy } & \multirow{7}{*}{$\mathrm{P} 1$} & GDP (billions) & P11 & + \\
\hline & & & Value added of the secondary sector (billions) & $\mathrm{P} 12$ & + \\
\hline & & & $\begin{array}{l}\text { Number of persons employed in the secondary sector } \\
\qquad(10,000)\end{array}$ & $\mathrm{P} 13$ & + \\
\hline & & & Average wage of active workers (yuan) & $\mathrm{P} 14$ & + \\
\hline & & & The number of industrial enterprises & P15 & + \\
\hline & & & Gross industrial output (billions) & P16 & + \\
\hline & & & Total investment in fixed assets (billions) & $\mathrm{P} 17$ & + \\
\hline & \multirow{2}{*}{ Energy consumption } & \multirow{2}{*}{ P2 } & Industrial electricity $(10,000 \mathrm{~kW} \cdot \mathrm{h})$ & $\mathrm{P} 21$ & - \\
\hline & & & Integrated energy consumption (10,000 tons/standard coal) & $\mathrm{P} 22$ & - \\
\hline \multirow{8}{*}{ State } & \multirow{3}{*}{$\begin{array}{l}\text { Discharge of the three } \\
\text { wastes }\end{array}$} & \multirow[b]{3}{*}{ S1 } & Total industrial waste water discharge (10,000 tons) & S11 & - \\
\hline & & & Industrial solid waste generation (10,000 tons) & S12 & - \\
\hline & & & $\begin{array}{c}\text { Total industrial waste gas emissions (billion standard cubic } \\
\text { meters) }\end{array}$ & S13 & - \\
\hline & \multirow{3}{*}{ Greenfield resources } & \multirow{3}{*}{ S2 } & Industrial fume (powder) dust emissions (tons) & S14 & - \\
\hline & & & Greening of built-up areas (hectares) & S21 & - \\
\hline & & & Forest cover $(\%)$ & S22 & + \\
\hline & \multirow[t]{2}{*}{ Air quality } & \multirow[t]{2}{*}{ S3 } & $\begin{array}{c}\text { Number of days with air quality at and better than level } 2 \\
\text { (days) }\end{array}$ & S31 & + \\
\hline & & & Particulate matter $(\mathrm{PM} 10)\left(\mu \mathrm{g} / \mathrm{m}^{3}\right)$ & S32 & - \\
\hline \multirow{6}{*}{ Response } & \multirow{3}{*}{ Governance facilities } & \multirow{3}{*}{ R1 } & Number of waste water treatment facilities (sets) & $\mathrm{R} 11$ & + \\
\hline & & & Number of industrial waste gas treatment facilities (sets) & $\mathrm{R} 12$ & + \\
\hline & & & Industrial sulfur dioxide removal (tons) & $\mathrm{R} 21$ & + \\
\hline & \multirow{3}{*}{ Governance capacity } & \multirow{3}{*}{$\mathrm{R} 2$} & Industrial fume (powder) dust removal (tons) & $\mathrm{R} 22$ & + \\
\hline & & & Combined industrial solid waste utilization $(10,000$ tons $)$ & $\mathrm{R} 23$ & + \\
\hline & & & $\begin{array}{l}\text { Product value of "three-wastes" comprehensive utilization } \\
\text { (10,000 yuan) }\end{array}$ & $\mathrm{R} 24$ & + \\
\hline
\end{tabular}

addition, the weight determination is subjective. Considering the intereffect of subsystems of the PSR model, we cannot solely measure indicators of the primary index and simply determine their impact weights. In this regard, this paper first classifies different types of indicators into "positive" and "negative" ones, uses the difference coefficient method to objectively calculate the weight of each type of indicators, applies the TOPSIS method to calculate the distance between the sample and the target, and then uses the grey correlation degree to calculate the industrial ecological development level. In fact, in the process of systematic evaluation of industrial ecosystems, not only is it necessary to measure the level of industrial ecology, but also it is more practical to understand the constraint factors in promoting industrial ecology levels for the 14 prefecturelevel cities in Liaoning Province to develop pathological diagnosis for industrial ecology. Therefore, this article introduces a constraint grade model to conduct an extension study on the development process of industrial ecology and diagnoses and analyses the constraint factors in the industrial ecology development of the cities in Liaoning Province. The calculation steps are as follows.

Normalization and assignment: $x_{i j}$ is the $j$-th evaluation index value in the $i$-th sample; $n$ is the number of samples; and $m$ is the number of indices. Because the different types of indices would affect development of industrial ecosystems either positively or negatively, it is necessary to normalize index values by applying the difference between the actual and target values and using the extreme value method:
Positive indices:

$$
r_{i j}=\frac{x_{i j}-\min _{i} x_{i j}}{\max _{i} x_{i j}-\min _{i} x_{i j}} .
$$

Negative indices:

$$
r_{i j}=\frac{\max _{i} x_{i j}-x_{i j}}{\max _{i} x_{i j}-\min _{i} x_{i j}},
$$

where $\max _{i} x_{i j}$ and $\min _{i} x_{i j}$ are the maximum and minimum values of the $j$-th index, respectively; after normalization, $r_{i j}$ is $[0,1]$.

Using the entropy value method to determine the weight of each index, then the weight of the $i$-th sample for the $j$-th index, $f_{i j}$, can be calculated:

$$
f_{i j}=\frac{r_{i j}}{\sum_{j=1}^{m} r_{i j}} \text {. }
$$

Calculate the entropy value of the $j$-th index $f_{j}$, i.e., $H_{j}$, as follows:

$$
H_{j}=-K \sum_{j=1}^{m} P_{j} \ln \left(P_{j}\right) .
$$

Calculate the entropy weight coefficient, i.e., $w_{j}$, as follows:

$$
w_{j}=\frac{1-H_{j}}{m-\sum_{j=1}^{m} H_{j}} .
$$


Build a weighted decision matrix, i.e., $V$, as follows:

$$
V=\left[\begin{array}{cccc}
v_{11} & v_{12} & \cdots & v_{1 j} \\
v_{21} & v_{22} & \cdots & v_{2 j} \\
\vdots & \vdots & & \vdots \\
v_{i 1} & v_{i 2} & \cdots & v_{i j}
\end{array}\right] .
$$

Determine the positive- and negative-ideal solutions, and calculate the Euclidean distance and grey correlation degree for all samples. The positive- and negative-ideal solutions are as follows:

$$
\begin{aligned}
& v_{j}^{+}=\left\{\max v_{i j} \mid i=1,2, \ldots, n\right\}=\left\{v_{1}^{+}, v_{2}^{+}, \ldots, v_{n}^{+}\right\}, \\
& v_{j}^{-}=\left\{\min v_{i j} \mid i=1,2, \ldots, n\right\}=\left\{v_{1}^{-}, v_{2}^{-}, \ldots, v_{n}^{-}\right\} .
\end{aligned}
$$

Then, the calculations for the Euclidean distance of either positive-ideal or negative-ideal solutions are as follows:

$$
\begin{aligned}
& D_{i}^{+}=\sqrt{\sum_{j=1}^{m}\left(v_{i j}-v_{j}^{+}\right)^{2}}, \quad i=1,2, \ldots, n, \\
& D_{i}^{-}=\sqrt{\sum_{j=1}^{m}\left(v_{i j}-v_{j}^{-}\right)^{2},} \quad i=1,2, \ldots, n .
\end{aligned}
$$

Calculate the grey correlation degree. The correlation coefficient for an index between the sample and the positiveideal solution can be calculated based on the weighted matrix:

$$
s_{i j}^{+}=\frac{\min _{i} \min _{j} \Delta v_{i j}+\rho \max _{i} \max _{j} \Delta v_{i j}}{\Delta v_{i j}+\rho \max _{i} \max _{j} \Delta v_{i j}},
$$

where $\Delta v_{i j}=\left|v_{j}^{+}-v_{i j}\right| ; \min _{i} \min _{j} \Delta v_{i j}$ is the minimum difference between two levels; $\max _{i} \max _{j} \Delta v_{i j}$ is the maximum difference between two levels; and $\rho \in[0,1]$ is resolution coefficient; in this study, $\rho=0.5$. Construct the grey correlation coefficient matrix of positive-ideal solution samples, and then calculate the grey correlation degree between each sample and the positive-ideal solution:

$$
W_{i}^{+}=\frac{\sum_{j=1}^{m} s_{i j}^{+}}{m}, \quad i=1,2, \ldots, n .
$$

Calculate the correlation coefficient of each sample and the negative-ideal solution on different indices:

$$
s_{i j}^{-}=\frac{\min _{i} \min _{j} \Delta v_{i j}+\rho \max _{i} \max _{j} \Delta v_{i j}}{\Delta v_{i j}+\rho \max _{i} \max _{j} \Delta v_{i j}},
$$

where $\Delta v_{i j}=\left|v_{j}^{-}-v_{i j}\right|$.

Calculate the grey correlation between each sample and the negative-ideal solution as follows:

$$
W_{i}^{-}=\frac{\sum_{j=1}^{m} s_{i j}^{+}}{m}, \quad i=1,2, \ldots, n .
$$

Calculate the relative proximity. Normalize the Euclidean distance and grey correlation as follows:

$$
\varepsilon_{i}=\frac{\delta_{i}}{\max _{1 \leq i \leq m}\left(\delta_{i}\right)}, \quad i=1,2, \ldots, n,
$$

where $\varepsilon_{i} \longrightarrow D_{i}^{+}, D_{i}^{-}, W_{i}^{+}, W_{i}^{-}$. After dimensionless processing, they are $d_{i}^{+}, d_{i}^{-}, w_{i}^{+}, w_{i}^{-}$.

The adjusted formula comprehensively considers the Euclidean distance and grey correlation:

$$
\begin{array}{ll}
T_{i}^{+}=\theta_{1} d_{i}^{-}+\theta_{2} w_{i}^{+}, & i=1,2, \ldots, n, \\
T_{i}^{-}=\theta_{1} d_{i}^{+}+\theta_{2} w_{i}^{-}, & i=1,2, \ldots, n,
\end{array}
$$

$\theta_{1}, \theta_{2}$ indicate the degree of preference, $\theta_{1}+\theta_{2}=1$; in this paper, $\theta_{1}=\theta_{2}=0.5 ; T_{i}^{+}$and $T_{i}^{-}$refer to how close the sample is to either the positive- or negative-ideal solutions.

Calculate the relative proximity, $\varepsilon_{i}$, as follows:

$$
\varepsilon_{i}=\frac{T_{i}^{+}}{T_{i}^{+}+T_{i}^{-}}, \quad i=1,2, \ldots, n .
$$

Calculate the constraint grade. Analyze and diagnose the study case by measuring the factor contribution, index deviation, and constraint grade: (1) factor contribution $\left(G_{j}\right)$ represents the degree of influence of single factor on the overall goal; (2) index deviation $\left(P_{j}\right)$ refers to the difference between a single factor index and the overall goal of the system, which is assumed as the difference between the standardized value of a single index and 100\%; (3) constraint grade $\left(Z_{j}\right)$ is the degree of influence of a single index or an index at criterion level on the development level of industrial ecosystems. The index deviation $P_{j}$ and the constraint grade $Z_{j}$ are calculated as follows:

$$
\begin{aligned}
& P_{i j}=1-r_{i j}, \\
& Z_{i j}=\frac{P_{i j} G_{j}}{\sum_{j=1}^{14} P_{i j} G_{j}} .
\end{aligned}
$$

\section{Results}

3.1. Spatiotemporal Evolution Characteristics of the Industrial Ecosystem's Development Level. According to the comprehensive evaluation methodology discussed above, we identified the positive- and negative-ideal solutions of indices, standardized the data using Excel, and conducted grey correlation analysis using MATLAB, thereby revealing the longitudinal characteristics of the development level of industrial ecosystems in the period of 2000 to 2018 for the 14 cities in Liaoning Province (see Figure 2). At the same time, based on ArcGIS software, we used the data in 2000, 2006, 2012, and 2018, respectively, to conduct a spatial visualization analysis of the development level of industrial ecology for all the cities in Liaoning Province, and then to clarify its spatial differentiation, as shown in Figure 3.

From Figure 2, the development level and situation of industrial ecosystems in the 14 cities of Liaoning Province varied in the study period but generally showed a steady upward trend. The industrial ecosystem's development level of these cities was in the range of $[0.38,0.66]$. Shenyang, the provincial capital city, and Dalian, a city specifically listed in the state economic plan, had relatively high levels of 


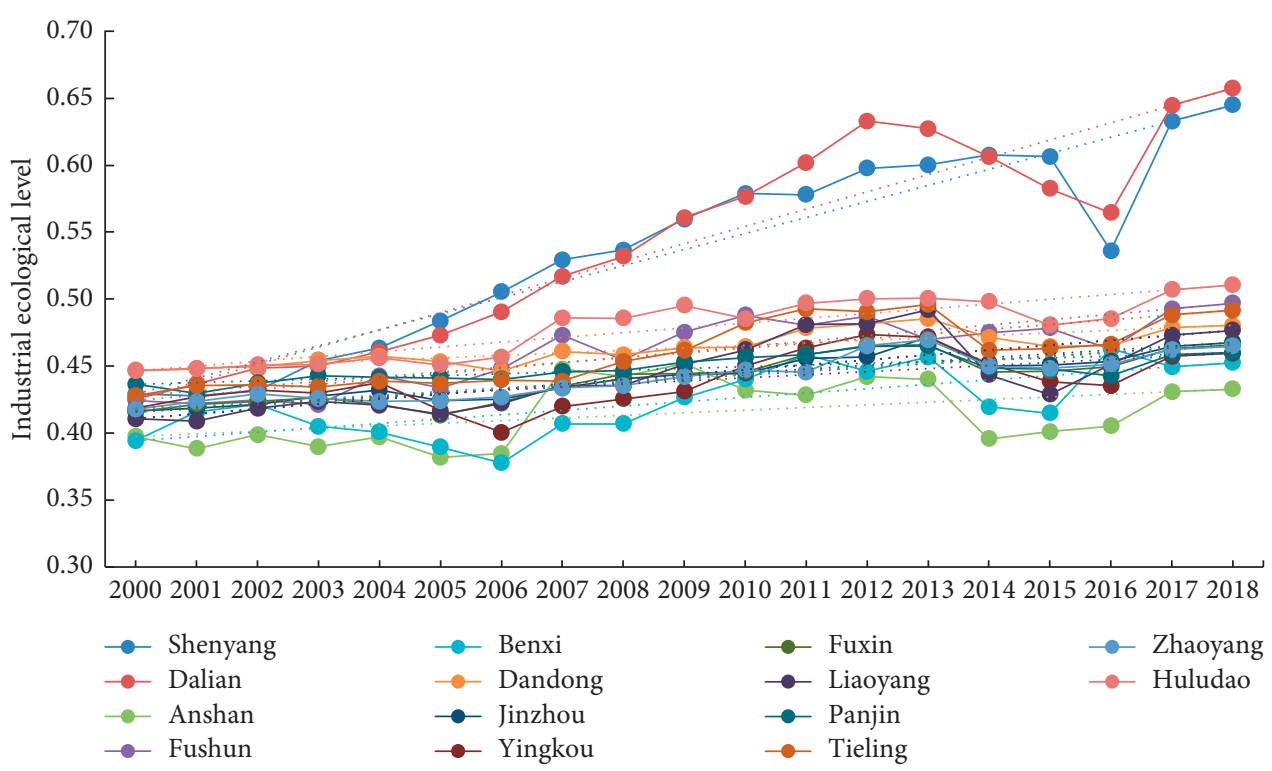

Figure 2: Development levels of industrial ecosystems in the 14 cities of Liaoning Province (2000-2018).

industrial ecosystem development, with an obvious upward trend and leading ahead, but they did not have a significant pull effect on the surrounding cities. Meanwhile, there was not a big difference in industrial ecology development among other cities, as they were all at a medium level. Liaoning Province, located in the old industrial region of Northeast China, is rich in natural resources but with a medium economic development level in China. Its economy has been dominated by resource-based industries for a long time, and the development of alternative industries was slow [46]. Except for Shenyang and Dalian, the difference in economic development among other cities was relatively small; moreover, the ability to adjust and reorganize the city's industrial ecosystem was limited and lagged by low ecological construction. From a longitudinal perspective, the development of industrial ecosystems in 2000-2006 was relatively stable; there was a rising trend from 2006 to 2013 , suggesting that the Revitalization Strategy had generated huge policy and investment effects. Since 2013, there was a trend of decline in industrial ecosystem's development. During the period when the GDP growth rates of all three northeastern provinces nationally ranked among the bottom ten, for example, ranking the bottom five in the year of 2014 and 2015, Liaoning Province, the largest economy in the Northeast, ranked nationally the lowest economic growth rate of $3.0 \%$ in 2015 and $-2.5 \%$ in 2016 , respectively. This period was called the "New Northeast Phenomenon," which had a significant negative impact on the industrial ecology development of the traditional industrial area in Northeast China especially in Liaoning Province.

From the prefecture-level city level, we conclude the following: (1) industrial ecosystem development in Shenyang and Dalian showed a rapid upward trend, and the development level was relatively high, leading the other 12 cities. This was closely related to the factors such as the administrative status, geographical location, and industrial structure of the two cities. Shenyang, as the central city of the three northeastern provinces, has policy advantage, large city size, and good market environment, thus attracts many high-end talents and quality enterprises, and leads the province in the overall development of Liaoning. Dalian is one of the high-tech industrial bases and a well-known tourist city in China. According to the 2010 China Urban Competitiveness Report, the comprehensive competitiveness of Dalian ranked the eighth among all cities in China. In Dalian, the solid technological foundation, first-class scientific and technological talent concentration, convenient sea \& land transportation, and comfortable climate \& environment promote its economic development and ecological construction. (2) Industrial ecosystem development in the five cities, i.e., Dandong, Jinzhou, Fuxin, Tieling, and Huludao, shows a steady upward trend with a fluctuation and is at medium level. Dandong is an important meeting point of the Northeast Asian Economic Circle, the Bohai Bay Economic Rim, and the Yellow Sea Economic Basin. It has currently formed advantageous industries such as transportation equipment manufacturing, agricultural \& sideline product processing, energy, metal mining, and smelting \& rolling processing. In recent years, to promote the development of industrial ecology, Dandong has successively established various ecological and environmental industrial parks and actively carried out ecological restoration projects. Both Jinzhou and Fuxin are important old industrial cities in Northeast China. Jinzhou has gradually formed an industrial system featuring petrochemicals, new materials, and deep processing of agricultural products. As one of the important cities in the Shenyang Economic Zone, Fuxin's industrial economy is dominated by coal. Dandong and Fuxin play a leading role in the overall development of the western Liaoning region, with a healthy development momentum. Tieling is one of the main grain production regions in China, a production and processing base of quality agricultural products, and an emerging coal-power city. Due to the characteristics of the industrial structure, the industrial 

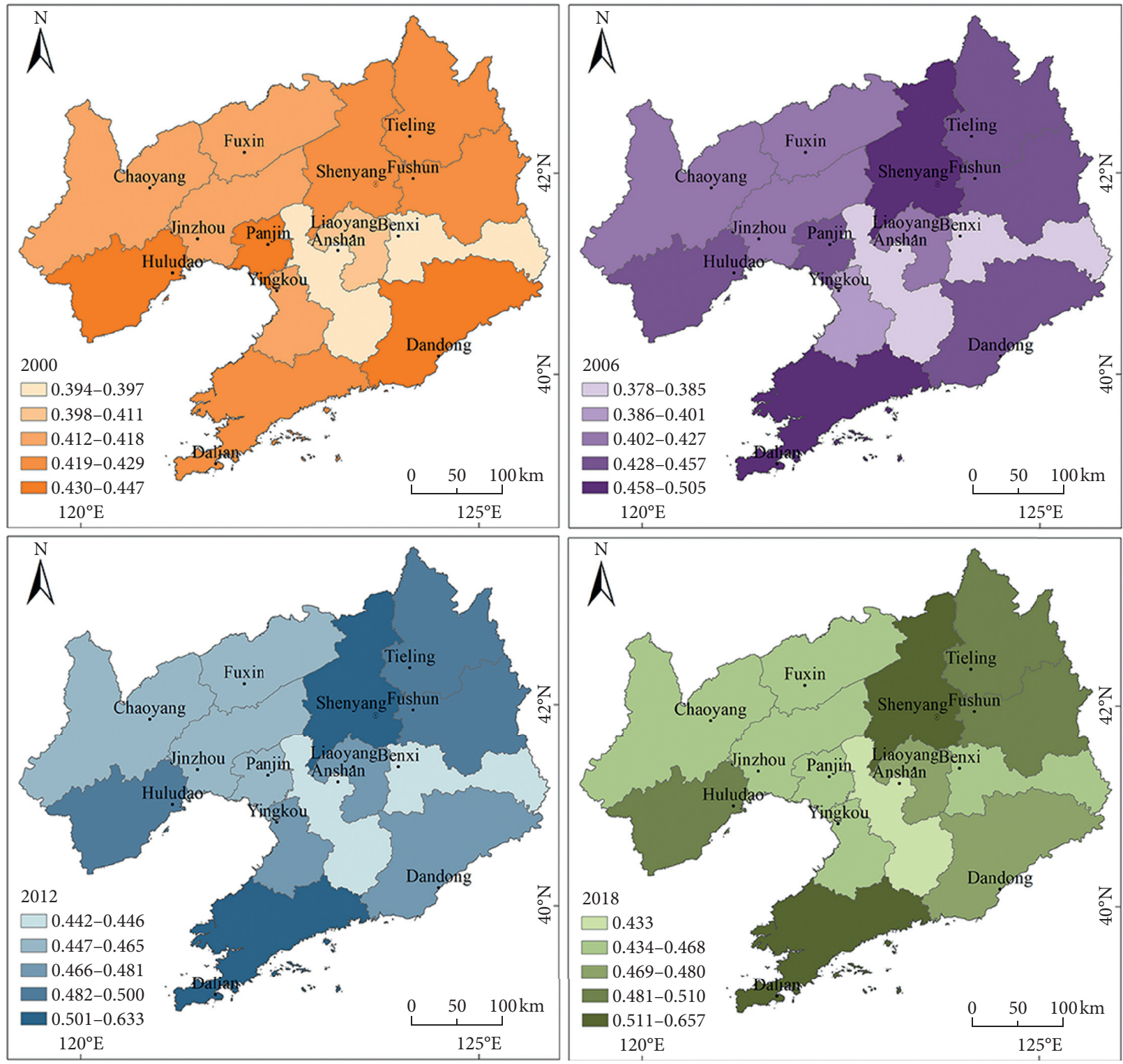

FIgURE 3: Spatiotemporal evolution patterns of urban industrial ecosystems development level in Liaoning Province.

ecosystem of Tieling is stable. Huludao is the west gate of Northeast China. With outstanding geographical advantages, it has formed a modern industrial system with such pillar industries as petrochemicals, nonferrous metals, machinery manufacturing, shipbuilding, and energy and power production. Based on a strong industrial development foundation, currently Huludao is in a critical transition period of industrial structure upgrade. (3) In the remaining 7 cities of Liaoning Province, i.e., Anshan, Fushun, Benxi, Yingkou, Liaoyang, Panjin, and Chaoyang, the development of industrial ecosystems shows a moderate upward trend, which is slightly weaker and more fluctuating than the overall development of the five cities mentioned above. Among them, the development of industrial ecosystems in Anshan, Benxi, and Yingkou has been in the most severe fluctuation, indicating that the stability of industrial ecosystems in these three cities is poor and needs to be adjusted effectively. There is no obvious change in industrial ecosystem development in Fushun, Liaoyang, Panjin, and Chaoyang. These four cities generally had a single industrial structure, poor environmental stability, and weak scientific and technological capacity. It is necessary and urgent to take effective measures to optimize the industrial ecosystem.

From the perspective of spatial distribution, the overall spatial differentiation was significant in 2000. Shenyang, Fushun, and Panjin in north-central Liaoning formed an "uplift belt," while Anshan, Liaoyang, and Benxi in the central-eastern province formed a "groove area." Since 2006, the spatial differentiation has become more significant, when Shenyang and Dalian have jointly formed a high-level industrial ecology zone. As the "dual-core" feature has been significant and increasingly strengthened, the agglomeration of Shenyang Economic Zone and Coastal Economic Belt was gradually enhanced, while the difference between the "uplift 
belt" and the "groove area" gradually dimmed. The industrial ecosystem's development level in the southeast has gradually surpassed that in the northwest. Anshan, a resource-depleted city, is slow in industrial transformation and remains a relatively low level of industrial ecosystem development, while Huludao City always maintains a high level. In terms of regional difference, there is a remarkable feature of "center-periphery" describing the central-northern region centered on Shenyang, and southeastern \& northwestern regions, respectively. To summarize the above analysis, both Shenyang Economic Zone and Liaoning Coastal Economic Belt are currently still the engines of industrial ecology development in the Northeast region, while the entire Northeast region has also achieved considerable development and the overall structure will be further optimized.

3.2. Cluster Analysis of Industrial Ecosystem. Based on the cluster analysis of the industrial ecology level for the 14 cities of Liaoning Province in 2018, the spatial distribution of high-level, medium-level, and low-level industrial ecosystems was identified. Through cluster analysis, we can conclude the following: (1) the two sub-provincial level cities, Shenyang and Dalian, have the high-level industrial ecosystem (industrial ecosystem development level $>0.55$ ). They have superior geographical locations, good industrial economic development conditions, and strong industrial foundations, which provide a strong guarantee for protecting the ecological environment. In the two cities, the green coverage in built-up areas is significantly higher than that of other cities; the industrial ecosystem development is at a higher level due to strong policy support. However, there is still room to improve the ability of ecological environmental governance; that is, there is potential to further develop the industrial ecology. (2) Huludao City has a medium-level industrial ecosystem $(0.5<$ development level of industrial ecosystem $\leq 0.55$ ). Huludao is a coastal city and has formed a modern industrial system with petroleum processing, non-ferrous metals, machinery manufacturing, ship building, and energy and power production as the pillar industries. Its industrial foundation is strong. However, due to the current situation of transitioning and upgrading industrial structure, various issues such as poor environmental stability and weak technological capacity have negatively affected the improvement of industrial ecosystem. (3) Eleven cities including Anshan, Fushun, and Benxi had a low-level industrial ecosystem (development level of industrial ecosystem $\leq 0.5$ ). Four cities in the Coastal Economic Belt of eastern Liaoning, i.e., Anshan, Yingkou, Panjin, and Jinzhou, are developing innovative industries and building a livable and touristic urban agglomeration. However, the traditional low-level industrial economy could not provide enough material, technical, and resource support for addressing ecological and environmental issues. Therefore, the environmental improvement is sluggish, and the process of sustainable development is slow. In Chaoyang, Tieling, and Fuxin, which locate in the northwest of Liaoning Province, the ecological and industrial development is not in harmony due to geographical constraints. The comprehensive competitiveness of these cities is at the lowest end of Liaoning Province with little development potential due to the limitation by geographical conditions and resource endowment. Insufficient motivation for industrial development leads to a low comprehensive level of industrial ecosystems. Fushun, Benxi, and Liaoyang are cities dominated by heavy industry, which strongly depend on heavy industry enterprises and have a weak economic foundation. The development of heavy industry caused a severe environmental pollution for these three cities. This incoordination in development of ecology and industry led to a relatively low level in integration of industrial and ecological development in the three cities. Dandong is a city bordering with North Korea; its foreign trade is relatively developed. However, due to a relatively late starting, there has not been a leading enterprise in the foreign trade that can drive the industrial development into a strong industrial cluster. Therefore, the added economic value is not significant, the growth rate is small, and the motivation in developing industry is still insufficient.

\subsection{Constraint Grade and Main Constraint Factors in In-} dustrial Ecosystem Development. Constraint factor analysis helps to formulate targeted measures to optimize the industrial ecosystem. In this study, we calculate the constraint grade for each specific index, indices at either criterion level or system level, as the results shown in Table 2. Further, from the perspective of time series, we analyze the change of main constraint factors and the difference of constraint factors among cities and diagnose the main constraint factors for the development level of industrial ecology in Liaoning Province, as the results shown in Table 3. At the same time, to identify the main constraints to the development of the industrial ecosystem within each city, we conduct a diagnosis of the main constraint factors for the development level of industrial ecology in 2018, as the results shown in Table 4.

As shown in Table 2, from a perspective of the level of constraints, the constraint grades of the subsystems of pressure, state, and response are $45.73 \%, 20.01 \%$, and $34.34 \%$, respectively, indicating that the main constraints affecting the development process of urban industrial ecosystems in Liaoning Province are the pressure of human activities on the environment and the inadequate measures taken by human in response to the ecological environment. (1) Constraint grade of the pressure subsystem. The constraint grade of the pressure subsystem to the development of industrial ecology is $45.73 \%$, suggesting that the pressure subsystem is the greatest constraint in the process of urban industrial ecology in Liaoning Province, among which the constraint grade of the criterion layer of industrial economy is $41.5 \%$, and the constraint grade of the criterion layer of energy consumption is $4.2 \%$. Within the pressure subsystem, many specific indices rank the top 10 by the constraint grade, including gross fixed asset investment $\left(\mathrm{P}_{17}\right), 6.74 \%$; gross industrial output value $\left(\mathrm{P}_{16}\right), 6.42 \%$; regional GDP $\left(\mathrm{P}_{11}\right)$, $6.17 \%$; added value of the secondary sector $\left(\mathrm{P}_{12}\right), 6.10 \%$; number of industrial enterprises $\left(\mathrm{P}_{15}\right), 5.92 \%$; number of 
TABLE 2: Measurements of constraint grade based on PSR model.

\begin{tabular}{|c|c|c|c|c|c|}
\hline System layer & Normative level & Barrier level & Indicator & Barrier level & Sort \\
\hline \multirow{9}{*}{ Pressure } & \multirow{7}{*}{ Industrial economy $\mathrm{P} 1$} & \multirow{7}{*}{0.415} & P11 & 0.0617 & 5 \\
\hline & & & $\mathrm{P} 12$ & 0.0610 & 6 \\
\hline & & & $\mathrm{P} 13$ & 0.0578 & 9 \\
\hline & & & $\mathrm{P} 14$ & 0.0437 & 14 \\
\hline & & & $\mathrm{P} 15$ & 0.0592 & 7 \\
\hline & & & P16 & 0.0642 & 3 \\
\hline & & & $\mathrm{P} 17$ & 0.0674 & 1 \\
\hline & \multirow[b]{2}{*}{ Energy consumption P2 } & \multirow{2}{*}{0.042} & $\mathrm{P} 21$ & 0.0193 & 18 \\
\hline & & & $\mathrm{P} 22$ & 0.0229 & 17 \\
\hline \multirow{8}{*}{ State } & \multirow{3}{*}{ Discharge of the three wastes P3 } & \multirow{4}{*}{0.052} & S11 & 0.0096 & 23 \\
\hline & & & S12 & 0.0096 & 22 \\
\hline & & & S13 & 0.0162 & 21 \\
\hline & \multirow{3}{*}{ Greenfield resources S2 } & & S14 & 0.0165 & 20 \\
\hline & & \multirow{2}{*}{0.098} & S21 & 0.0589 & 8 \\
\hline & & & S22 & 0.0386 & 15 \\
\hline & \multirow{2}{*}{ Air quality S3 } & \multirow{2}{*}{0.051} & S31 & 0.0183 & 19 \\
\hline & & & S32 & 0.0323 & 16 \\
\hline \multirow{6}{*}{ Response } & \multirow{2}{*}{ Governance facilities R1 } & \multirow{2}{*}{0.103} & $\mathrm{R} 11$ & 0.0499 & 13 \\
\hline & & & $\mathrm{R} 12$ & 0.0528 & 12 \\
\hline & \multirow{4}{*}{ Governance capacity R2 } & \multirow{4}{*}{0.241} & $\mathrm{R} 21$ & 0.0654 & 2 \\
\hline & & & $\mathrm{R} 22$ & 0.0543 & 11 \\
\hline & & & $\mathrm{R} 23$ & 0.0572 & 10 \\
\hline & & & $\mathrm{R} 24$ & 0.0638 & 4 \\
\hline
\end{tabular}

TABLE 3: Main constraint factors of industrial ecosystem development of 14 cities in Liaoning Province during 2000-2018.

\begin{tabular}{lcccccccccc}
\hline Year & $\begin{array}{c}\text { Barrier } \\
\text { factor }\end{array}$ & $\begin{array}{c}\text { Barrier } \\
\text { level }\end{array}$ & $\begin{array}{c}\text { Barrier } \\
\text { factor }\end{array}$ & $\begin{array}{c}\text { Barrier } \\
\text { level }\end{array}$ & $\begin{array}{c}\text { Barrier } \\
\text { factor }\end{array}$ & $\begin{array}{c}\text { Barrier } \\
\text { level }\end{array}$ & $\begin{array}{c}\text { Barrier } \\
\text { factor }\end{array}$ & $\begin{array}{c}\text { Barrier } \\
\text { level }\end{array}$ & $\begin{array}{c}\text { Barrier } \\
\text { factor }\end{array}$ & $\begin{array}{c}\text { Barrier } \\
\text { level }\end{array}$ \\
\hline 2000 & P16 & 0.0811 & P17 & 0.0807 & P11 & 0.0793 & R21 & 0.0756 & P12 & 0.0748 \\
2001 & P17 & 0.0745 & R21 & 0.0728 & P16 & 0.0706 & P11 & 0.0709 & P15 & 0.0699 \\
2002 & P17 & 0.0748 & R21 & 0.0730 & P16 & 0.0709 & P11 & 0.0709 & P15 & 0.0699 \\
2003 & P17 & 0.0748 & R21 & 0.0746 & P16 & 0.0718 & P11 & 0.0706 & P15 & 0.0701 \\
2004 & R21 & 0.0766 & P17 & 0.0757 & R24 & 0.0724 & P16 & 0.0722 & P11 & 0.0711 \\
2005 & R21 & 0.0818 & P17 & 0.0747 & R24 & 0.0739 & P16 & 0.0713 & P11 & 0.0703 \\
2006 & R21 & 0.0849 & R24 & 0.0771 & P17 & 0.0757 & P11 & 0.0711 & R23 & 0.0711 \\
2007 & R21 & 0.0900 & P17 & 0.0811 & R24 & 0.0765 & P11 & 0.0761 & P16 & 0.0759 \\
2008 & R21 & 0.0920 & P17 & 0.0804 & R24 & 0.0802 & P11 & 0.0758 & P16 & 0.0758 \\
2009 & R21 & 0.0961 & R24 & 0.0871 & S32 & 0.0837 & R23 & 0.0821 & P17 & 0.0818 \\
2010 & R24 & 0.0959 & R21 & 0.0930 & R23 & 0.0865 & S32 & 0.0823 & P17 & 0.0777 \\
2011 & R24 & 0.0935 & R21 & 0.0898 & R23 & 0.0890 & S32 & 0.0868 & P17 & 0.0798 \\
2012 & R24 & 0.0995 & R21 & 0.0957 & R23 & 0.0938 & P21 & 0.0935 & S32 & 0.0898 \\
2013 & P21 & 0.1119 & R23 & 0.1021 & R24 & 0.1013 & S32 & 0.0958 & R21 & 0.0921 \\
2014 & S31 & 0.1027 & R24 & 0.0992 & P21 & 0.0965 & S11 & 0.0945 & R23 & 0.0934 \\
2015 & P16 & 0.1022 & R24 & 0.0999 & S31 & 0.0922 & R23 & 0.0878 & S32 & 0.0866 \\
2016 & P16 & 0.0984 & R21 & 0.0912 & P15 & 0.0887 & P17 & 0.0844 & R23 & 0.0806 \\
2017 & R24 & 0.1035 & P21 & 0.0996 & R23 & 0.0973 & R21 & 0.0970 & S32 & 0.0932 \\
2018 & R24 & 0.1059 & P21 & 0.1049 & R23 & 0.0994 & R21 & 0.0982 & S32 & 0.0957 \\
\hline
\end{tabular}

Note. Only the top five constraint factors are listed in the table.

employees in the secondary sector $\left(\mathrm{P}_{13}\right), 5.78 \%$. They all fall into the category of industrial economy. Thus, it can be revealed that the overall low level of industrial economic development is the main constraint hindering the development of industrial ecosystems in Liaoning Province. Inadequate capital investment, declining economic growth, and loss of human resources lead to low levels of industrial ecosystem development. On the other hand, due to economic downturn, excess energy production capacity, and insufficient development motivation, at the criterion layer of energy consumption, the constraint grade is only $4.3 \%$. (2) Constraint grade of the state subsystem. The constraint grade of state subsystem to the development of industrial ecology is $20.01 \%$, proportionally small in comparison with that of "pressure" and "response" subsystems. In this subsystem, only the green coverage in the built-up area $\left(\mathrm{S}_{21}\right)$ ranks in the top 10 indices regarding the constraint grade, i.e., 5.89\%, ranking eighth. This suggests that, in the state 
TABLE 4: Main constraint factors of industrial ecosystem development of 14 cities in Liaoning Province in 2018.

\begin{tabular}{|c|c|c|c|c|c|c|c|c|c|c|}
\hline \multirow[b]{2}{*}{ Area } & \multicolumn{2}{|c|}{1} & \multicolumn{2}{|c|}{2} & \multicolumn{2}{|c|}{3} & \multicolumn{2}{|c|}{4} & \multicolumn{2}{|c|}{5} \\
\hline & $\begin{array}{l}\text { Barrier } \\
\text { factor }\end{array}$ & $\begin{array}{c}\text { Barrier } \\
\text { level }\end{array}$ & $\begin{array}{l}\text { Barrier } \\
\text { factor }\end{array}$ & $\begin{array}{c}\text { Barrier } \\
\text { level }\end{array}$ & $\begin{array}{l}\text { Barrier } \\
\text { factor }\end{array}$ & $\begin{array}{c}\text { Barrier } \\
\text { level }\end{array}$ & $\begin{array}{l}\text { Barrier } \\
\text { factor }\end{array}$ & $\begin{array}{c}\text { Barrier } \\
\text { level }\end{array}$ & $\begin{array}{l}\text { Barrier } \\
\text { factor }\end{array}$ & $\begin{array}{c}\text { Barrier } \\
\text { level }\end{array}$ \\
\hline Shenyang & $\mathrm{R} 24$ & 0.1059 & $\mathrm{R} 21$ & 0.0982 & S32 & 0.0957 & $\mathrm{R} 23$ & 0.0850 & $\mathrm{P} 21$ & 0.0791 \\
\hline Dalian & $\mathrm{P} 21$ & 0.1049 & $\mathrm{R} 23$ & 0.0994 & $\mathrm{R} 24$ & 0.0943 & P22 & 0.0867 & S11 & 0.0814 \\
\hline Anshan & $\mathrm{R} 21$ & 0.0691 & $\mathrm{R} 24$ & 0.0670 & P22 & 0.0638 & P17 & 0.0543 & P21 & 0.0533 \\
\hline Fushun & P17 & 0.0747 & P13 & 0.0691 & $\mathrm{P} 11$ & 0.0684 & $\mathrm{P} 15$ & 0.0680 & P16 & 0.0677 \\
\hline Benxi & $\mathrm{R} 24$ & 0.0711 & P17 & 0.0671 & P15 & 0.0651 & $\mathrm{R} 21$ & 0.0646 & P13 & 0.0624 \\
\hline Dandong & $\mathrm{R} 24$ & 0.0751 & $\mathrm{R} 21$ & 0.0748 & P16 & 0.0718 & P17 & 0.0710 & P13 & 0.0695 \\
\hline Jinzhou & $\mathrm{R} 21$ & 0.0688 & P17 & 0.0678 & $\mathrm{~S} 22$ & 0.0659 & $\mathrm{R} 24$ & 0.0656 & P13 & 0.0651 \\
\hline Yingkou & P13 & 0.0657 & P17 & 0.0651 & $\mathrm{R} 21$ & 0.0647 & $\mathrm{~S} 21$ & 0.0604 & P16 & 0.0597 \\
\hline Fuxin & P17 & 0.0742 & P16 & 0.0723 & $\mathrm{P} 12$ & 0.0701 & P11 & 0.0700 & P13 & 0.0681 \\
\hline Liaoyang & P17 & 0.0741 & P13 & 0.0722 & P15 & 0.0686 & $\mathrm{R} 24$ & 0.0684 & $\mathrm{R} 21$ & 0.0679 \\
\hline Panjin & $\mathrm{R} 21$ & 0.0753 & $\mathrm{R} 24$ & 0.0715 & $\mathrm{R} 23$ & 0.0658 & P15 & 0.0657 & P17 & 0.0640 \\
\hline Tieling & $\mathrm{R} 21$ & 0.0742 & P17 & 0.0741 & P13 & 0.0728 & P12 & 0.0721 & S21 & 0.0721 \\
\hline Zhaoyang & $\mathrm{R} 21$ & 0.0730 & $\mathrm{R} 24$ & 0.0711 & $\mathrm{P} 17$ & 0.0704 & $\mathrm{~S} 21$ & 0.0694 & P16 & 0.0684 \\
\hline Huludao & $\mathrm{P} 17$ & 0.0815 & $\mathrm{P} 16$ & 0.0785 & P15 & 0.0776 & $\mathrm{P} 12$ & 0.0759 & $\mathrm{P} 11$ & 0.0757 \\
\hline
\end{tabular}

Note. Only the top five constraint factors are listed in the table.

subsystem, green space resources have a greater impact on the development of industrial ecosystems. Meanwhile, no indices at the criterion level of three-wastes emission and air quality are ranked in the top 10. Overall, the constraint grade of either the damage caused by "three-wastes" emissions or the maintenance sustained by green space resources to the ecological environment, or the status of air quality because of destruction and maintenance, is within the controllable range for industrial ecosystem development. In the future industrial development process, priority must be given to strengthening the protection of existing green space resources, and strictly controlling over excessive land development. (3) Constraint grade of the response subsystem. The constraint grade of the response subsystem to development of industrial ecology is $34.34 \%$. Among them, at the criterion level, the constraint grade of governance facility is $10.3 \%$ while that of governance ability is $24.1 \%$, suggesting that the criterion level of governance ability is the main constraint factor in the response subsystem. In this subsystem, those indices ranking in the top 10 include industrial sulfur dioxide removal $\left(\mathrm{R}_{21}\right)$ with a constraint grade of $6.54 \%$, output value of "three-wastes" comprehensive utilization products $\left(\mathrm{R}_{24}\right)$ with a constraint grade of $6.38 \%$, and comprehensive utilization of industrial solid waste $\left(\mathrm{R}_{23}\right)$ with a constraint grade of $5.72 \%$. This indicates that cities in Liaoning Province generally have problems in the pollution treatment at the end of industrial production process, such as insufficient investment in treatment, weak treatment capability, and low comprehensive utilization rate of wastes.

As shown in Table 3, from a perspective of main constraint factors, longitudinally, during the 19 years from 2000 to 2018, the main constraint factors in the process of industrial ecology development in cities of Liaoning Province were industrial sulfur dioxide removal $\left(\mathrm{R}_{21}\right)$, output value of "three-wastes" comprehensive utilization products $\left(\mathrm{R}_{24}\right)$, gross fixed asset investment $\left(\mathrm{P}_{17}\right)$, gross industrial output value $\left(\mathrm{P}_{16}\right)$, comprehensive utilization of industrial solid waste $\left(\mathrm{R}_{23}\right)$, regional GDP $\left(\mathrm{P}_{11}\right)$, inhalable particulate matter
(PM10) $\left(\mathrm{S}_{32}\right)$, industrial electricity consumption $\left(\mathrm{P}_{21}\right)$, number of days with air quality reaching or better than Class II $\left(S_{31}\right)$, number of industrial enterprises $\left(P_{15}\right)$, gross industrial wastewater discharge $\left(S_{11}\right)$, etc. However, the ranking of these major constraint factors changed significantly with time. Among them, the ranking of industrial sulfur dioxide removal $\left(\mathrm{R}_{21}\right)$ and gross fixed asset investment $\left(\mathrm{P}_{17}\right)$ gradually decreased, while the ranking of the output value of "three-wastes" comprehensive utilization products $\left(R_{24}\right)$ fluctuated; but all these three always ranked in the top three. In recent years, these cities in Liaoning Province have actively responded to the central government's call for successively adopting a series of measures to control air pollution and the emission of sulfur dioxide in factories, which has achieved positive outcomes. The comprehensive utilization of "three-wastes" influences recycling resources and easing environmental pressure, but the current "threewastes" comprehensive utilization production is associated with issues such as high capital investment, difficult processing, and low product quality, which greatly constrains the industrial ecosystem development. The highly temporal consistency of the main constraint factors of different cities indicates that the differences among the cities were insignificant.

From Table 4, due to a significant difference in regional economies among the cities, the main constraint factors for the development of the industrial ecosystems were also significantly different. However, the main constraint factors in Fushun, Fuxin, and Huludao were similar, mainly including regional GDP $\left(\mathrm{P}_{11}\right)$, number of employees in the secondary sector $\left(\mathrm{P}_{13}\right)$, gross industrial output value $\left(\mathrm{P}_{16}\right)$, gross fixed asset investment $\left(\mathrm{P}_{17}\right)$, etc. The top 5 indices for the three cities were all the pressure subsystem; i.e., the pressure subsystem became the main constraint factor. Moreover, for these three cities, there were no strong industrial foundations, the urban construction was backward, professional elites and talents had moved out to provide workforce for other cities, the economy lacked vitality, and 
the urban comprehensive competitiveness was at the bottom of Liaoning Province. Shenyang and Dalian had similar main constraint factors, mainly including industrial electricity consumption $\left(\mathrm{P}_{21}\right)$, comprehensive utilization of industrial solid waste $\left(\mathrm{R}_{23}\right)$, and output value of "threewastes" comprehensive utilization products $\left(\mathrm{R}_{24}\right)$, etc. The response subsystem was the main constraint factor. On the one hand, the two cities have strong industrial foundations and superior geographical locations and have the most developed industrial economies in the province. However, on the other hand, the ecological environment was not paid enough attention to and investment in environmental management was not enough in these two cities, which caused greater constraints to governance capacity than to industrial ecology. The main constraint factors in Anshan, Benxi, Dandong, Jinzhou, Liaoyang, and Chaoyang cities were similar, mainly including number of employees in the secondary sector $\left(\mathrm{P}_{13}\right)$, gross fixed asset investment $\left(\mathrm{P}_{17}\right)$, industrial sulfur dioxide removal $\left(\mathrm{R}_{21}\right)$, output value of "three-wastes" comprehensive utilization products $\left(\mathrm{R}_{24}\right)$, etc. The six cities were at a medium development level in the province, in terms of either urbanization or competitiveness of the industrial economy. In recent years, due to the policy advantage and the pull effect from economic development of Shenyang and Dalian, the economy developed rapidly in the six cities. However, without a continuous improvement of necessary supporting systems such as employment market and urban construction, the governance capacity was limited. At present, the six cities should mainly strengthen talent introduction and urban infrastructure construction and investment and simultaneously emphasize both economic development and environmental governance to overcome constraints to industrial ecology development. The main constraint factors for Yingkou and Tieling cities were similar, mainly including number of employees in the secondary sector $\left(P_{13}\right)$, gross fixed asset investment $\left(P_{17}\right)$, green coverage of the built-up area $\left(\mathrm{S}_{21}\right)$, and industrial sulfur dioxide removal $\left(R_{21}\right)$. Benefiting from the strategic layout of the Eastern Liaoning Coastal Economic Zone, Yingkou City had enjoyed preferential policies and achieved a rapid economic development. However, there was still a shortage in quality workforce and urban construction investment. Moreover, the green coverage of the built-up area and the governance capacity of Yingkou were insufficient. These issues constrained the economic development in Yingkou City. Tieling, a remotely located city, had neither a strong industrial foundation nor a large-scale trade exchange. In addition, the labor force was insufficient. Thus, its industrial economy, ecological environment, and governance capacity were all in an embarrassing situation. Regarding spatial scale, the main constraint factors affecting the internal industrial ecosystem's development in 14 cities of Liaoning Province were the pressure and response subsystems, while the state subsystem had little impact. Although all the cities had made a great progress in actively responding to the central government's call for controlling environmental pollution, it is yet to take urgent actions in energizing industrial economic development motivation and improving environmental governance capabilities for all cities.

\section{Discussion and Conclusions}

4.1. Discussion. The industrial ecosystem consists of both various elements that have an important impact on the development of an industry and multiple interactions of these elements. It is an organic system composed of various participants along the industrial chain, the supporting factors of industrial development and the external environment which the survival and development of an industry rely on. Establishment of a mature industrial ecosystem enables symbiosis, mutualism, and regeneration of industrial elements to maximize the economic and social values $[47,48]$. Industrial development is the result of collective effects of entire industrial ecosystem [46]. Competition among regional economies is a competition for industrial ecology. Those regions who can firstly establish the complete industrial ecosystem will take an advantage in economic development. Currently, formation of industrial ecology exhibits two major characteristics: first, enterprises in the same industry or industry cluster gather in a geographical region to form an industrial agglomeration; second, local leading enterprises with unique products and competitiveness expand its development based on its business model. Such expansion drives the growth of individual ecological elements in surrounding areas and forms a business ecosystem. A fundamental reason why China's super central cities, i.e., Beijing, Shanghai, Guangzhou, and Shenzhen, can maintain high growth is the establishment of a good industrial ecology. In these cities, the competition has changed from "industry" to "industrial ecology." Moreover, the trend of specialization and verticalization of industrial ecology is becoming more and more obvious. To manifest this trend, economic growth points are continuously emerging, major breakthroughs are continuously made in emerging industries and technological innovation, innovative and emerging industries are incubated and nurtured, and a group of unicorn enterprises are born as industry leaders that race to control the commanding heights of economy in China or even in the globe. In contrast, in many third- and fourth-tier cities, economic growth is slow. It is partly because of yet-toimprove industrial ecology that lacks attractiveness to resources such as talents, capital, and technology, lacks innovative environment, and thus results in the loss of endogenous economic growth. The premise of constructing a sound industrial ecology is to clearly define the industrial positioning, realize the industrial agglomeration, and organically integrate industrial elements to catalyze their "ecological chemical reaction." With popularized application of big data, cloud computing, Internet of Things, and intelligent hardware, the industrial ecology is being digitally empowered and flattened managed, industrial elements are closely interconnected and collaborated in an efficient and intelligent way, and finally the industrial value chain is being reshaped. Despite this, it is still necessary to take measures from multiple dimensions to increase support for industrial ecology. For example, we should improve the construction 
of innovative ecosystems [49], strengthen the support for ecological elements such as land [50], and take consideration of responses to climate change $[51,52]$. We must break the information barriers among research institutions, universities, government departments, business organizations, and financial institutions, optimize the business environment, strengthen policy guidance, and actively promote the integration of industry-education-research and the transformation of research outcomes, thus to form a marketoriented and enterprise-based innovation system. In addition, it is a wise choice to introduce third-parties to gather industrial talents and resources, where a platform-type industrial organization is particularly important for the construction of regional industrial ecology. Through such a platform, it is possible to establish connection with various resources including talents, scientific research, capital, and market, and further to establish a network with upstream and downstream enterprises. This would greatly reduce the difficulties in attracting investment and energize the dynamics of industrial elements.

Liaoning Province, as a representative and typical province of the traditional industrial area in Northeast China, has been accelerating the transformation and optimization of traditional industries since the implementation of the Revitalization Strategy. Economic development in Liaoning has shifted from high-speed growth to high-quality development. While major equipment design and manufacturing industry is leading the country, a regional innovation system is gradually taking shape. However, due to a long-term influence of the extensive economic growth model, the traditional industry development model, and the conservative management system and mechanism, the industrial development pattern has not yet fundamentally changed, which is still mainly based on traditional industries such as equipment manufacturing, coal mining, and petroleum smelting. Meanwhile, there still exist many problems in urban industrial ecology in Liaoning Province. Firstly, there is a lack of a top-level design of industrial ecosystem planning. Governments and enterprises at all levels overemphasize industrial development but fail to organically integrate industry into industrial ecosystem development, which results in a sole industrial system, lack of connection between industrial categories, slow development of industrial ecology, and convergence of industrial structure. Consequently, the complementary effect of regional advantages is not effectively exerted, and the regional competitiveness is compromised. Secondly, there is not a strong capability in independent innovation of industrial ecosystems. Till now, Liaoning still heavily depends on traditional industrial paths, without enough nurture of emerging pillar industries, featuring a low level of industrial structure and an overweighed secondary sector. Meanwhile, there is a lack of effective dynamic circulation system, hightech industries and modern service industries are proportionally low, the industry of deep processing of raw material is less developed, and the independent innovation ability is weak. Thirdly, there is no feedback mechanism for the practice of industrial ecosystems. In the process of industrial development, most traditional industries are still characterized by the unidirectional consumption of energy resources and the degradation of ecological environmental service functions. There is a lack of standards and methods to systematically assess economic-environmental dynamics. Without having established a feedback mechanism to regulate a healthy development of industrial ecosystems, it is impossible to effectively integrate resources for building a modern economic system.

Constructing industrial ecosystems is a new strategic measure to promote a comprehensive revitalization of the Northeast Region. It can effectively address deep-seated issues in industrial development of the traditional industrial area in Liaoning, overcome constraints of traditional industrial development systems and mechanisms, change the industrial development approach in multiple dimensions such as management mechanism, operation mode, production method, and business environment, and realize an economic-environmental coupling and sustainable development. It is also an important pathway leading to an effective transformation of economic development in Liaoning. In this regard, Liaoning Province should pay more attention to the industrial ecosystem construction and take it as a focus to promote the industrial development in a green, circular, and quality way. Some recommendations and suggestions are as follows: firstly, deepen the reform of systems and mechanisms to create a good business environment for industrial ecosystem construction. It is necessary to properly handle the government-market relationship, focusing on addressing such issues as government's direct intervention in resource allocation, overmanagement, and the misalignment, offside, absence, and inadequacy of governmental functions, and further promote simplified administration, decentralization, and optimization of services. Continue to deepen the reform of administrative approval systems, commercial systems, and investment and financing systems. Perform government functions according to law to accelerate the establishment and improvement of the management model based on the power lists, the responsibility lists, and the negative lists. Improve the legitimate decision-making mechanism and strengthen the restriction and supervision of power. Secondly, unleash the potential in regional collaborative innovation to build technological innovation capabilities for industrial ecosystem construction. Formulate and implement a system that encourages technological innovation and intellectual property protection, improve the innovation and entrepreneurship service model, and provide full-chain value-added services for innovation and entrepreneurship activities to stimulate the independent innovation capabilities in the traditional industrial area in Liaoning. Thirdly, strengthen the top-level design of regional collaborative development to broaden development space for industrial ecosystem construction. Aim to construct industrial ecosystems, integrate the spatial distribution of industrial development in the province, and plan the industrial ecosystem construction based on regional macro-policies to establish a regional macro ecosystem integrating industry, agriculture, services, and high-technology. Fourthly, innovate and enhance the supply capacity of ecological products to provide a 
material foundation for industrial ecosystem construction. Deploy in advance the development strategy for alternative, clean, and green industries, make full use of unique ecological resources, combine with rural revitalization strategies, energize new dynamics of rural resource development, to transform superior ecological resources into high-quality ecological product supply and ecological services, and realize ecological industrialization. Fifthly, engage a multi-party participation mechanism to provide scientific support for industrial ecosystem construction. Promote the knowledge and cognition of the industrial ecosystem to make enterprises aware of the importance and advantages of industrial ecosystem construction through education \& training, media promotion, and the Internet. Strengthen scientific support by organizing an expert team to research industrial ecosystems of the traditional industrial area in Liaoning, which is an interdisciplinary team engaging multiple stakeholders including governments, enterprises, research institutions, and universities, to provide multi-dimensional support for industrial ecosystem construction of the traditional industrial area in Liaoning, from policy recommendation, to top-level design, and then to the application of industrial ecological technology.

4.2. Conclusions. This paper took 14 cities in Liaoning Province as examples of urban industrial ecosystems of traditional industrial area in Northeastern China to calculate the development level of its industrial ecosystem during 2000-2018 using an improved Topsis method, and to conduct a spatial visualization analysis, which provides new perspectives and methods for analyzing and interpreting the complexity of urban industrial ecosystems. The results show the following: (1) from 2000 to 2018, the 14 cities in Liaoning Province had a moderate level of industrial ecology. Except for Shenyang and Dalian with rapid development, the difference in the development level of industrial ecosystems among other cities was small. (2) From 2000 to 2018, the development level of industrial ecosystems in cities first increased and then decreased, with some fluctuation. The development level of the industrial ecology in these cities generally showed an upward-then-downward trend. Regarding spatial differentiation, a high-level industrial ecological zone formed with Shenyang and Dalian as the center. The "dual-core" feature was significant and continuously strengthened. As a result, the whole region exhibited a "center-periphery" pattern. (3) At the system level of PSR, the constraint grades to the industrial ecosystem's development level in the 14 cities of Liaoning Province were different. The constraint grades of the pressure, state, and response subsystems to the province's industrial ecosystem were $45.73 \%, 20.01 \%$, and $34.34 \%$, respectively, indicating that the main constraint factors affecting the process of urban industrial ecology in Liaoning Province were both the lack of human response to the ecological environment and the pressure of human activities on the ecological environment during the industrial economic development. (4) Due to the large differences in geographical environments, economic bases, industrial structures, and development circumstances among different cities, the main constraint factors to development of industrial ecosystems were also significantly different; but overall, regional GDP, number of employees in the secondary sector, gross fixed asset investment, industrial sulfur dioxide removal, and output value of "three-wastes" comprehensive utilization product were the main five factors. With popularized application of big data, cloud computing, Internet of Things, and intelligent hardware, the main direction of further research in the future may point to reshaping the industrial value chain, improving and innovating the ecosystem construction, and introducing third-party forces to gather industrial talents and resources for creating an industrial symbiosis network on a city scale. However, to fully and scientifically understand the complexity of the urban industrial ecosystem, it is necessary not only to study at the element level, but also to systematically recognize the complexity of the network structure, establish a structural model to analyze its evolutionary dynamics, and then guide the formulation of industrial policy for the development of regional industrial ecology, which will be the main research direction in the future.

\section{Data Availability}

The data used to support the findings of this study are available from the corresponding author upon request.

\section{Conflicts of Interest}

The authors declare that they have no conflicts of interest.

\section{Acknowledgments}

The authors thank the Natural Science Foundation of China (41701142 and 41971166), Fundamental Research Funds for the Central Universities (2020jbkyjc002), Project of Gansu Province, Economic and Social Development Serving of Lanzhou University (2019-FWZX-04), and Open Project of Institute of County Economy Developments \& Rural Revitalization Strategy, Lanzhou University (xyjj2019002).

\section{References}

[1] T. E. Graedel and B. R. Allenby, Industrial Ecology, Prentice Hall, Englewood Cliffs, NJ, USA, 1995.

[2] B. R. Allenby and W. E. Cooper, "Understanding industrial ecology from a biological systems perspective," Environmental Quality Management, vol. 3, no. 3, pp. 343-354, 1994.

[3] S. Charmondusit, K. Bhaktikul, C. Arunlertaree, W. Wisawapipat, C. Rattanapan, and K. Charmondusit, "Problem based training program on industrial ecology and environment for the sustainability management of industry," Procedia-Social and Behavioral Sciences, vol. 40, pp. 31-36, 2012.

[4] R. A. Frosch and N. E. Gallopoulos, "Strategies for manufacturing," Scientific American, vol. 261, no. 3, pp. 144-152, 1989.

[5] Y. Huang, C. Lu, X. Xiao et al., "Evolution and reconstruction of industrial ecosystems of mining cities in the traditional industrial area of Northeastern China: a case study of 
Dashiqiao in Liaoning Province," Chinese Journal of Ecology, vol. 37, no. 10, pp. 3146-3154, 2018.

[6] D. Wang and Y. Gao, "Competitive evolution and coevolution," Chinese Journal of Ecology, vol. 24, no. 10, pp. 11821186, 2005.

[7] R. Zhang and X. Qian, "Research on regional industrial ecosystem and its ecological properties," R\&D Management, vol. 21, no. 1, pp. 45-50, 2009.

[8] M. Li, "Complexity evolutionary analysis of Beijing industrial system," China Market, vol. 52, pp. 90-101, 2016.

[9] Y. Xiao, The Optimization of Spatial Analysis Model in Complex Urban Conditions, Dalian University of Technology, Dalian, China, 2015.

[10] L. Chen, R. Wang, J. Yang, and Y. Shi, "Structural complexity analysis for industrial ecosystems: a case study on LuBei industrial ecosystem in China," Ecological Complexity, vol. 7, no. 2, pp. 179-187, 2010.

[11] Z. Zhou, Research on Complex Adaptive Systems for Ecological Industries, Tsinghua University, Beijing, China, 2005.

[12] F. Dong, Y. Wang, L. Zheng, J. Li, and S. Xie, "Can industrial agglomeration promote pollution agglomeration? Evidence from China," Journal of Cleaner Production, vol. 246, Article ID 118960, 2020.

[13] P. Wu, G. Guang, Z. Kong et al., "The evolvement and cultivation of industrial eco-system based on self-organization of system," Chinese Journal of Nature, vol. 30, no. 6, pp. 354-358, 2008.

[14] M. Fuji, T. Fujita, L. Dong et al., "Possibility of developing low-carbon industries through urban symbiosis in Asian cities," Journal of Cleaner Production, vol. 114, pp. 376-386, 2016.

[15] Y. Zhang, W. Lu, V. Wing-Yan Tam, and Y. Feng, "From urban metabolism to industrial ecosystem metabolism: a study of construction in Shanghai from 2004 to 2014," Journal of Cleaner Production, vol. 202, pp. 428-438, 2018.

[16] L. Wang, X. Dong, X. Liu, and H. Yin, “A quantitative study on the coordinative relationship between tourism and development of eco-civilized city in Dunhuang," Ecological Science, vol. 36, no. 4, pp. 194-201, 2017.

[17] E. A. Lowe and L. K. Evans, "Industrial ecology and industrial ecosystems," Journal of Cleaner Production, vol. 3, no. 1-2, pp. 47-53, 1995.

[18] F. Qiu, L. Tong, and M. Jiang, "Adaptability assessment of industrial ecological system of mining cities in Northeast China," Geographical Research, vol. 30, no. 3, pp. 243-255, 2011.

[19] C. Lu, Study on System Evolution and Symbiosis Effects of Industrial Symbiosis-Case of Jinchang, Lanzhou University, Lanzhou, China, 2013.

[20] H. Ruoslahti, "Complexity in project co-creation of knowledge for innovation," Journal of Innovation \& Knowledge, vol. 4, 2020 .

[21] J. Fan, S. Hu, D. Chen, and Y. Zhou, "Study on the construction and optimization of a resource-based industrial ecosystem," Resources, Conservation and Recycling, vol. 119, pp. 97-108, 2017.

[22] J. Rosenhead, L. A. Franco, K. Grint, and B. Friedl, "Complexity theory and leadership practice: a review, a critique, and some recommendations," The Leadership Quarterly, vol. 30, no. 5, Article ID 101304, 2019.

[23] Q. Zhao and X. Shi, "Characteristics and evolution of an urban industrial ecological network: a case study of Beijing," Acta Ecologica Sinica, vol. 37, no. 14, pp. 4873-4882, 2017.
[24] R. U. Ayres, "Industrial metabolism," in Technology and Environment, J. H. Ausubel and H. E. Sladovich, Eds., pp. 23-49, National Academics Press, Washington, DC, USA, 1989.

[25] S. S. Chopra and V. Khanna, "Understanding resilience in industrial symbiosis networks: insights from network analysis," Journal of Environmental Management, vol. 141, pp. 86-94, 2014.

[26] S. Chen and B. Chen, "Network environ perspective for urban metabolism and carbon emissions: a case study of Vienna, Austria," Environmental Science \& Technology, vol. 46, no. 8, pp. 4498-4506, 2012.

[27] R. V. Berkel, T. Fujita, S. Hashimoto, and Y. Geng, "Industrial and urban symbiosis in Japan: analysis of the eco-town program 1997-2006," Journal of Environmental Management, vol. 90, no. 3, pp. 1544-1556, 2009.

[28] Q. Zhu, E. A. Lowe, Y. Wei, and D. Barnes, "Industrial symbiosis in China: a case study of the Guitang Group," Journal of Industrial Ecology, vol. 11, no. 1, pp. 31-42, 2007.

[29] M. Zhang, Research on the Forming Machanism and Stability of Industrial Symbiosis Network, Harbin Institute of Technology, Harbin, China, 2008.

[30] J. Huang and R. E. Ulanowicz, "Ecological network analysis for economic systems: growth and development and implications for sustainable development," PLoS One, vol. 9, no. 6, Article ID e100923, 2014

[31] Y. Zhang, H. Zheng, B. D. Fath et al., "Ecological network analysis of an urban metabolic system based on input-output tables: model development and case study for Beijing," Science of the Total Environment, vol. 468-469, pp. 642-653, 2014.

[32] W. Wang and T. Zhou, "Eco-economic system of the Chinese industry," Journal of Southeast University (Philosophy and Social Science), vol. 17, no. 4, pp. 73-78, 2015.

[33] B. Xue, L. Zhang, Y. Geng et al., "Spatial-restructuring analysis of human-land relationships in an old industrial area: the case of the Tiexi district, Shenyang," Scientia Geographica Sinica, vol. 35, no. 7, pp. 890-897, 2015.

[34] H. Li and P. Zhang, "The evolution and coping timing of economic vulnerability of mining cities: a case study in Northeast China," Economic Geography, vol. 34, no. 1, pp. 82-88, 2014.

[35] F. Dong, J. Li, K. Li et al., "Causal chain of haze decoupling efforts and its action mechanism: evidence from 30 provinces in China," Journal of Cleaner Production, vol. 10, 2020.

[36] C. Lu, B. Xue, C. Lu et al., "Sustainability investigation of resource-based cities in Northeastern China," Sustainability, vol. 8, no. 10, p. 1058, 2016.

[37] B. Xue, L. Zhang, Y. Geng, Yong, B. Mitchell, and W. Ren, "Extended land use categories in urban brownfield re-development of China: case of Tiexi district, Shenyang of China," Journal of Urban Planning and Development, vol. 142, no. 3, pp. 1-11, 2016.

[38] Q. Yang, C. Lu, F. Zhou et al., "An emergy-ecological footprint model-based evaluation of ecological security at the old industrial area in Northeast China: a case study of Liaoning province," Chinese Journal of Applied Ecology, vol. 27, no. 5, pp. 1594-1602, 2016.

[39] C. Tang, C. Lu, Q. Yang et al., "Dynamic evolution and driving forces of ecological security in the traditional industrial area of Northeastern China," Acta Ecologica Sinica, vol. 37, no. 22, pp. 7474-7482, 2017.

[40] C. L. Hwang and K. Yoon, Multiple Attribute Decision Making-Methods and Applications a State-of-the-Art Survey, Springer, Berlin, Germany, 1981. 
[41] B. Li and X. Jin, "Spatio-temporal evolution of marine Fishery industry ecosystem vulnerability in the Bohai Rim region," Chinese Geographical Science, vol. 29, no. 6, pp. 1052-1064, 2019.

[42] A. Guo, J. Yang, X. Xiao, J. Xia, C. Jin, and X. Li, "Influences of urban spatial form on urban heat island effects at the community level in China," Sustainable Cities and Society, vol. 53, Article ID 101972, 2020.

[43] J. Yang, S. Jin, X. Xiao et al., "Local climate zone ventilation and urban land surface temperatures: towards a performancebased and wind-sensitive planning proposal in megacities," Sustainable Cities and Society, vol. 47, pp. 1-11, 2019.

[44] S. Jin, J. Yang, E. Wang, and J. Liu, "The influence of highspeed rail on ice-snow tourism in northeastern China," Tourism Management, vol. 78, Article ID 104070, 2020.

[45] L. Li, P. Zhang, K. Lo, W. Liu, and J. Li, "The evolution of regional economic resilience in the old industrial bases in China: a case study of Liaoning province, China," Chinese Geographical Science, vol. 30, no. 2, pp. 340-351, 2020.

[46] Z. Morris, M. Weissburg, and B. Bras, "Towards a biologicallyinspired urban-industrial ecosystem," Procedia CIRP, vol. 69, pp. 861-866, 2018.

[47] B. Tonn, P. D. Frymier, D. Stiefel, L. S. Skinner, N. Suraweera, and R. Tuck, "Toward an infinitely reusable, recyclable, and renewable industrial ecosystem," Journal of Cleaner Production, vol. 66, pp. 392-406, 2014.

[48] J. Yang, Y. Bao, Y. Zhang, X. Li, and Q. Ge, "Impact of accessibility on housing prices in Dalian city of China based on a geographically weighted regression model," Chinese Geographical Science, vol. 28, no. 3, pp. 505-515, 2018.

[49] E. Susur, A. Hidalgo, and D. Chiaroni, "The emergence of regional industrial ecosystem niches: a conceptual framework and a case study," Journal of Cleaner Production, vol. 208, pp. 1642-1657, 2019.

[50] P. Zhang, Y. Li, W. Jing et al., "Comprehensive assessment of the effect of urban built-up land expansion and climate change on net primary productivity," Complexity, vol. 2020, Article ID 8489025, 12 pages, 2020.

[51] C. Lu, W. Ren, L. Jiang, and B. Xue, "Modelling impact of climate change and air pollution in cities," Proceedings of the Institution of Civil Engineers-Engineering Sustainability, vol. 170, no. 3, pp. 133-140, 2016.

[52] B. Xue, "Honing the climate change message," Science, vol. 348 , no. 6237 , p. 872, 2015. 